\title{
The impact of age on post-operative outcomes of colorectal cancer patients undergoing surgical treatment
}

\author{
Tadas Latkauskas*1, Giedre Rudinskaité2 ${ }^{2}$ Juozas Kurtinaitis², \\ Rasa Jančiauskiené ${ }^{3}$, Algimantas Tamelis ${ }^{1}$, Žilvinas Saladžinskas ${ }^{1}$ and \\ Dainius Pavalkis ${ }^{1}$
}

\author{
Address: ${ }^{1}$ Unit of Coloproctology, Department of Surgery, Kaunas Medical University Clinics, Eiveni 2, Kaunas, Lithuania, ${ }^{2}$ University of Vilnius, \\ Institute of Oncology, Santariskiu 1, Vilnius, Lithuania and '3Department of oncology, Kaunas Medical University, Eiveni 2, Kaunas, Lithuania \\ Email: Tadas Latkauskas* - Tadas.Latkauskas@kmuk.lt; Giedrė Rudinskaitė - grudinsk@yahoo.com; Juozas Kurtinaitis - jkurtinaitis@mail.lt; \\ Rasa Jančiauskienè - Rasa.Janciauskiene@kmuk.lt; Algimantas Tamelis - kp@kmu.lt; Žilvinas Saladžinskas - kp@kmu.lt; \\ Dainius Pavalkis - dainius@kmu.lt \\ * Corresponding author
}

Published: 02 December 2005

BMC Cancer 2005, 5:153 doi:10.1186/147|-2407-5-153
Received: 25 July 2005

Accepted: 02 December 2005

This article is available from: http://www.biomedcentral.com/I47I-2407/5/153

(c) 2005 Latkauskas et al; licensee BioMed Central Ltd.

This is an Open Access article distributed under the terms of the Creative Commons Attribution License (http://creativecommons.org/licenses/by/2.0), which permits unrestricted use, distribution, and reproduction in any medium, provided the original work is properly cited.

\begin{abstract}
Background: the purpose of study was to evaluate the impact of age on outcomes in colorectal cancer surgery.

Methods: patients on hospital database treated for colorectal cancer during the period $1995-$ 2002 were divided into two groups: Group I - patients of 75 years or older $(n=154)$, and Group 2 - those younger than 75 years $(n=532)$.

Results: In Group I, for colon cancers, proximal tumors were significantly more common (23\% vs. $13.5 \%, p<0.05)$, complicated cases were more frequent ( $46 \%$ vs. $33 \%, p=0.002)$, bowel obstruction more common at presentation $(40 \%$ vs. $26.5 \%, p=0.00 \mathrm{I})$, and more frequent emergency surgery required $(24 \%$ vs. $14 \%, p=0.003)$. Postoperative overall morbidity was higher in the elderly group, but with no differences in surgical complications rate. Overall 5 year survival was $39 \%$ vs. $55 \%(p=0.0006)$ and cancer related 5 year survival was $44 \%$ vs. $62 \%(p=0.0006)$. Multivariate Cox analysis showed that age was not an independent risk factor for postoperative mortality.
\end{abstract}

Conclusion: Preoperative complications and co-morbidities, more advanced disease, and higher postoperative nonsurgical complication rates adversely affect postoperative outcomes after surgery for colorectal cancer in the elderly.

\section{Background}

Colorectal cancer is a disease of elderly, with only $5 \%$ recorded in those younger than 40 years. Elderly patients form a highly heterogeneous group in respect of both general physical status, and number and types of co-morbidities $[1,2]$. This, to some degree, has resulted in different concepts in management, not only from surgical and anesthesiological perspectives, but also from the expectancy of uneventful recovery and long term survival, combined with acceptable quality of life. Historically, it was suggested that elderly patients do not fare well after surgery for colorectal cancer, with high rates of emergency 
Table I: Age, gender, location of the tumours and TNM classification;

\begin{tabular}{|c|c|c|c|}
\hline & Groupl (age $\geq 75$ years; $n=154$ ) & Group2 (age < 75 years; $\mathrm{n}=532$ ) & $P$ \\
\hline Median age & $80.7 \pm 4.7$ & $58.29 \pm 9.9$ & 0,02 \\
\hline \multicolumn{4}{|l|}{ Gender } \\
\hline Male & 73 & 270 & 0.5 \\
\hline Female & 81 & 262 & \\
\hline \multicolumn{4}{|l|}{ Location } \\
\hline Rectum & $65(42 \%)$ & $212(39.8 \%)$ & 0.45 \\
\hline Colon & $88(58 \%)$ & $319(60 \%)$ & \\
\hline sigmoid & $42(27 \%)$ & $170(32 \%)$ & 0.24 \\
\hline descendens & $3(2 \%)$ & $17(3 \%)$ & 0.4 \\
\hline left angle & $5(3.2 \%)$ & $12(2.2 \%)$ & 0.5 \\
\hline transversum & $2(1.2 \%)$ & $48(9 \%)$ & 0.001 \\
\hline Right colon: & $36(23 \%)$ & $72(13.5 \%)$ & 0.04 \\
\hline right angle & $7(4.5 \%)$ & $18(3 \%)$ & 0.5 \\
\hline ascendens & $19(14 \%)$ & $35(6.5 \%)$ & 0.02 \\
\hline caecum & $10(6.4 \%)$ & $19(4 \%)$ & 0.1 \\
\hline \multicolumn{4}{|l|}{ TNM stage } \\
\hline T3-4 & $464(87 \%)$ & $129(83.7 \%)$ & 0.2 \\
\hline $\mathrm{N}+$ & $62(40 \%)$ & $193(36 \%)$ & 0.02 \\
\hline$M+$ & $40(25 \%)$ & $127(23 \%)$ & 0.4 \\
\hline
\end{tabular}

presentations, inoperability and peri-operative mortality [3], although more recent publications have encouraged the same surgical approach as for younger patients $[2,4,5]$. The purpose of this study was to evaluate impact of age on colorectal cancer presentation, surgical management and outcomes from a single institution serving a population of approximately 2 million over a six year period.

\section{Methods}

Data of all patients treated in Kaunas Medical University Hospital for colorectal cancer during 1996 - 2002 were collected retrospectively and prospectively. Data included: age; gender; location of the tumor; TNM classification; operative risk factors; whether surgery was performed in the emergency or elective settings; incidence of radical or palliative resections; and the short-term and long-term outcomes. Postoperative mortality was defined as death occurring within the first 30 days after operation. All patients were followed up in the outpatient department and were also seen by a consultant oncologist for consideration of adjuvant therapy. A decision to give adjuvant therapy was based on tumour stage, biological age of the patient and co-morbid risk factors. The Lithuanian Cancer Register supplied the date and cause of death of those who died during the follow-up period. Statistical analysis was made using SPSS package. The chi-square or Fisher exact tests were used for comparison of categorical variables between the groups. Cox analysis was used to identify independent factors for postoperative mortality.

\section{Results}

Over the six year period, 686 patients with colorectal cancer were treated. They were divided on the basis of age into two groups: Group 1 included 154 patients (23\%) with ages of 75 years and older, and Group 2 included 532 patients $(77 \%)$, under 75 years of age.

\section{Demographics (Table I)}

The median age in Group 1 was $80.7 \pm 4.7$ years, and $58.29 \pm 9.9$ in Group2. There was no significant difference in gender ratio. There were no differences in ratio of colonic to rectal tumors between the two groups (Group 1: $89(58 \%)$ colonic, $65(42 \%)$ rectal; Group 2: 320 $(60 \%)$ colonic, $212(39 \%)$ rectal, p > 0.05). However, amongst colonic tumors, proximal lesions (caecum, ascending colon, hepatic flexure and proximal transverse colon) were significantly commoner in Group 1 (36 (23\%); Group 2: 72 (13.5\%), ( $=0.04)$.

When compared in respect of tumor stage, the only significant difference lay in nodal status, which was more advanced in Group 1 (node positive disease: Group 1: 62 (40\%); Group $2: 193$ (36\%), $(\mathrm{p}=0.02)$.

\section{Complications and surgery}

Overall preoperative complications (Table 2) were diagnosed in $72(46 \%)$ patients in Group 1, compared with $176(33 \%)$ in Group $2(\mathrm{p}=0.002)$, the commonest being bowel obstruction (Group 1: 62 (40\%); Group 2: 141 
Table 2: Preoperative complications, co-morbidity, ASA (American Society of Anesthesiologists) distribution and procedures performed;

\begin{tabular}{lccc}
\hline & Group I (age $\geq 75$ years; $n=154)$ & Group 2 (age <75 years; $n=532)$ & $P$ \\
\hline Preoperative complications: & $72(46 \%)$ & $176(33 \%)$ & 0.002 \\
Obstruction & $62(40 \%)$ & $141(26.5 \%)$ & 0.001 \\
Perforation & 8 & 28 & 0.47 \\
Co-morbidity & $123(80 \%)$ & $296(55 \%)$ & 0.0001 \\
ASA 3-5 & 111 & 248 & 0.0001 \\
Surgery & & & \\
$\quad$ Emergency & $38(24 \%)$ & $77(14 \%)$ & 0.003 \\
$\quad$ Curative & $104(68 \%)$ & $384(82 \%)$ & 0,2 \\
$\quad$ Palliative & $50(32 \%)$ & $148(18 \%)$ & 0,01 \\
$\quad$ Resection rate & $131(85 \%)$ & $481(90 \%)$ &
\end{tabular}

(26.5\%), $\mathrm{p}=0.001)$. Co-morbidities were more frequent amongst the elderly patients $80 \%$ vs. $55 \%(\mathrm{p}=0.0001)$, with more patients in Group 1 classified as ASA 3-5 ( $\mathrm{p}=$ 0.0001 ). Emergency surgery (mainly because of bowel obstruction, or perforation) was performed in 115 (17\%) patients overall (Table 2), but was more frequent within the elderly (Group 1: 38(24\%); Group 2: 77(14\%), p = $0.003)$.

On the basis of preoperative staging and surgeon decision concerning radicality, $68 \%$ of patients underwent resection with curative intent in group 1, compared with $82 \%$ in group $2(\mathrm{p}=0.2)$. However, the resection rate was lower in elderly group $-85 \%$ vs. $90 \%(\mathrm{p}=0.01)$, with palliative colostomy or by-pass surgery performed in $16(10 \%)$ patients in Group 1, compared with 20 (3.7\%) in Group $2(\mathrm{p}=0.0001)$. There were no other differences between the two groups with regard to the type of operation.

Postoperative complications were recorded in 57(37\%) patients in the elderly cohort, compared with 164 (30\%) in the younger group ( $\mathrm{p}>0.05)$, although general complications (pneumonia, pulmonary failure, pulmonary embolism, arrhythmia, myocardial infarction, cardiovascular failure and urinary infection) were more frequent in the elderly (Group 1: 34 (22\%); Group 2: 73 (13.7\%), p = $0.02)$. There were no differences between the groups in surgical complication rate (Group 1: 24 (15.5\%); Group 2: $91(17 \%), p=0.6)$, either in the elective or emergency setting (Table 3 ), but the general non-surgical complica- tion rate was higher after elective surgery in the elderly (Group 1: 22 (18.9\%); Group 2: 53 (11.6\%), p = 0.04).

\section{Survival}

The postoperative mortality rate was $11 \%(\mathrm{n}=18)$ in elderly group, compared with $5 \%(n=26)$ in the younger cohort $(\mathrm{p}=0.002)$. The influence of age, TNM stage, ASA distribution, emergency operation and etc. on postoperative mortality were evaluated using Multivariate Cox analysis. The age was not an independent risk factor for postoperative mortality in mentioned analysis.

Two year survival (Figure 1) in the elderly group was 55\%, compared with $67 \%$ in group $2(\mathrm{p}=0.004)$. Five year survival was respectively $39 \%$ and $55 \%,(p=0.0006)$. Cancer related survival (Figure 2) at 2 years was $59 \%$ vs. $70 \%$ (p $=0.004)$, and at 5 years, $44 \%$ vs. $62 \%(\mathrm{p}=0.0006)$.

\section{Discussion}

No standard definition of "elderly" exists, with different authors using thresholds of $65[2,6], 70[7,8,16], 75$ $[9,10], 80[2,4]$ and 85 years [17]. Data from the Lithuanian Office of National Statistics [11] shows that average life expectancy in Lithuania is 71.66 years, 65.88 years for men, and 77.41 years for women. We selected 75 years as the threshold, because it is more than Lithuanian medium life expectancy, and such a division creates a so called elderly group which constitutes approximately one quarter of all colorectal cancer patients, as used in other studies [2]. "Biological" age in different nationalities and populations

Table 3: Post-operative complications

\begin{tabular}{|c|c|c|c|c|c|c|}
\hline & $\begin{array}{c}\text { age } \geq 75 \text { years; } n=38 ; \\
\text { emergency }\end{array}$ & $\begin{array}{c}\text { age }<75 \text { years; } \mathrm{n}=77 ; \\
\text { emergency }\end{array}$ & $P$ & $\begin{array}{c}\text { age } \geq 75 \text { years; } n=116 ; \\
\text { elective }\end{array}$ & $\begin{array}{c}\text { age }<75 \text { years; } n=455 ; \\
\text { elective }\end{array}$ & $P$ \\
\hline Overall morbidity & $19(50 \%)$ & 44 (57.1\%) & 0,4 & 38 (32.7\%) & $120(26.4 \%)$ & 0,17 \\
\hline General compl. & $12(31.6 \%)$ & 20 (25.9\%) & 0,5 & 22 (18.96\%) & 53 (II.6\%) & 0,04 \\
\hline Surgical compl. & 7 (I8.4\%) & $24(31.2 \%)$ & 0,14 & $17(14.6 \%)$ & 67 (14.7\%) & 0,9 \\
\hline
\end{tabular}




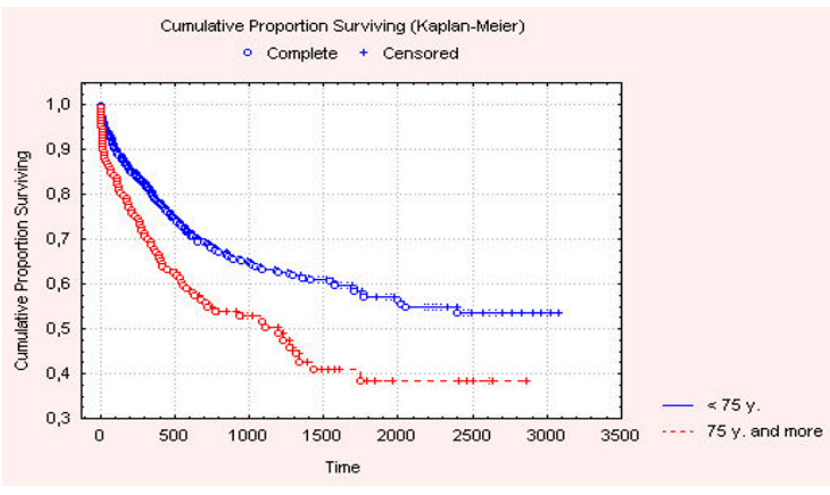

Figure I

Overall survival of patients.

varies, and it is reasonable that a 75 year old Lithuanian is equivalent to an 80 year old Western European, or 85 year old Japanese, due to differing life expectancies of these populations, although more detailed demographic assessments would be necessary to validate such assumptions.

Previous studies have demonstrated an age-related right shift of colorectal cancer [12,13], this supported by the present study. Marush et al. reported ageing was associated with more locally advanced tumors, but not with metastatic dissemination [2]. This study revealed only differences in nodal status, but no differences between the groups in T stage. However, mechanical bowel obstruction (the most common preoperative complication in both groups), a clinical indicator of locally advanced disease was more frequent in the elderly group. Acute presentation was more frequent in the elderly group, with emergency surgery performed in $24 \%$ of such patients, compared to $14 \%$ in younger group ( $p=0.003)$, similar to previous studies reported $[2,17]$.

Our study has confirmed that the majority of complications arising in the surgical management of elderly patients with colorectal cancer are not truly surgical, but of a more general nature, both pre- and post-operatively, the latter perhaps compounded by less than optimal preoperative preparation. Menke et al. [14] reported a comorbidity of $28.1 \%$ in patients older than 80 years, and Wolters et al. [8] incidences of $49 \%$ for hypertension, $18 \%$ for coronary heart disease, and 39\% for pulmonary disease, equivalent to our total co-morbidity frequency of $80 \%$, compared to $55 \%$ in the younger patient group $(\mathrm{p}=$ $0.0001)$.

Resection rates for elderly patients are usually slightly lower than in younger patients, due to preoperative complications and co-morbidities, and more extensive tumors $[2,4,17]$. Nevertheless, advances made in surgical tech- nique, anesthetic and postoperative intensive care have resulted in an increase in possibility to perform surgery from $80 \%$ up to $95 \%$ of cases [16]. The resection rate in our study was $85 \%$ in the elderly, comparing with $90 \%$ in those younger than 75 years $(\mathrm{p}=0.01)$, with a concomitant increase in the rates of palliative colostomy formation and by-pass procedures in the elderly $(10 \%$ vs. $3.7 \%),(p=0.0001)$. The recorded reasons for not performing resection included locally advanced disease, presence of preoperative complications and co-morbidities, and emergency nature of the surgery. Postoperative morbidity and mortality is a significant source of concern in the management of the elderly patient with colorectal cancer. Postoperative morbidity is governed by a higher incidence of general complications rate $[2,17]$, with specific surgical postoperative complications occurring at no greater frequency than in younger patients [2]. The difference in rates of general complications following elective surgery, but not after emergency surgery is more difficult to explain.

Overall mortality was $11 \%$ in the elderly group, compared with $5 \%$ in those under 75 years old $(\mathrm{p}=0.002)$. Emergency surgery for colorectal carcinoma in the elderly is associated with higher morbidity and mortality, reported rates varying between $6 \%$ and $38 \%$ for emergency operations and $0.9 \%$ and $18 \%$ for elective operations in those over 70 [7]. The risk of postoperative death in patients over 80 years rises to $11.9-38 \%$ after emergency surgery, and $7.4-11.4 \%$ in elective cases $[7,8]$, making the postoperative mortality rates of the present study acceptable.

Overall survival is, not surprisingly, poorer in the elderly, but any differences are much less strong when expressed as cancer related survival rates $[4,15]$. The overall 2-years and 5 -years survival rate in patients over 75 years of age was lower than that observed in younger patients in the present study, perhaps due to the lower frequency of curative operations, and the higher proportion of deaths from other causes in the elderly group. Barrier et al. [4] reported that in those patients operated with curative intent, the 5-year cancer-specific survival rate was not significantly different between the two age groups. Unfortunately the results of the present study do not support this; it is possible however, that a registered cause of death as cancer, without detailed evaluation or postmortem examination, was in fact incorrect.

\section{Conclusion}

In Lithuania, patients with colorectal cancer have similar demographic profiles as those in other countries. Based on a threshold of 75 years, preoperative complication and emergency surgery rates are more common in elderly patients, but postoperative surgical morbidity rates are similar to those observed in younger patients. Postopera- 


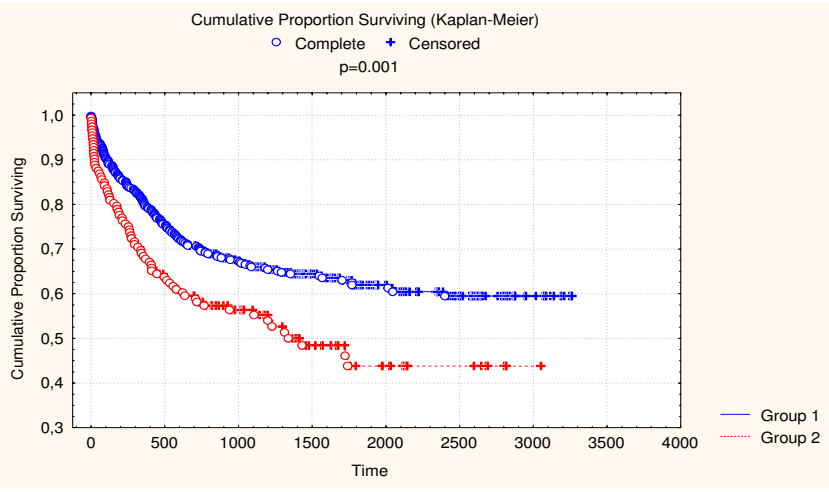

Figure 2

Cancer related survival. (Group I < 75 years).

tive non-surgical morbidity was higher in the elderly group, which influenced postoperative mortality. Overall survival was better in younger patients and the same difference remained in cancer specific long term survival.

\section{Competing interests}

The author(s) declare that they have no competing interests.

\section{Authors' contributions}

TL abstracted data, made data analysis, drafted and revised the manuscript.

GR collected data, performed statistical analysis.

JK participated in data extraction from Lithuanian cancer registry.

RJ collected and abstracted data, participated in the planning of the study.

AT participated in the planning of the study and coordinated the writing of the manuscript.

ZS participated in the planning of the study and coordinated the writing of the manuscript.

DP participated in the planning of the study and coordinated the writing and approved the final manuscript.

All authors read and approved the final manuscript.

\section{References}

I. Ries LAG, Eisner MP, Kosary CL, editors, et al.: SEER cancer statistics review, 1973-1997 Bethesda, MD: Nacional Cancer Institute, NIH Pub. No.00-2789; 2000.

2. Marusch F, Koch A, Schmidt U, Zippel R, Gastmeier K, et al.: Impact of age on the short- term postoperative outcome of patients undergoing surgery for colorectal carcinoma. Colorectal Dis 2002, 17:177-184.
3. Rankin FW, Johnson CC: Major operations in elderly patients. Surgery 1939, 5:763-774.

4. Barrier A, Ferro L, Houry S, Lacaine F, Huguire M: Rectal cancer surgery in patients more than $\mathbf{8 0}$ years of age. The American J of Surg 2003, 185:54-57.

5. Sunouchi K, Namiki K, Mori M, et al.: How should patients $\mathbf{8 0}$ years of age or older with colorectal carcinoma be treated? Long-term and short-term outcome and postoperative cytokine levels. Dis Colon Rectum 2000, 43(2):233-24I.

6. Paksoy M, Ipek T, Colak T, Cebeci H: Influence of age on prognosis and management of patients with colorectal carcinoma. Eur J Surg 1999, 165:55-59.

7. Waldron R, Donovan I, Drumm J, Mottram S, Tedman S: Emergency presentation and mortality from colorectal cancer in the elderly. Br J of Surg 1986, 73:2 I4-2।6.

8. Wolters $U$, Isenberg J, Stutzer $\mathrm{H}$ : Colorectal carcinoma - aspects of surgery in the elderly. Anticancer Res 1997, 17:1273-1276.

9. Tomoda H, Tsujitani S, Furusawa M: Surgery for colorectal cancer in elderly patients- a comparison with younger adult patients. Jpn J Surg 1998, 18:397-402.

10. Makela J, Kiviniemi H, Laitinen S: Survival after operations for colorectal cancer in patients aged 75 years and over. Eur J Surg 2000, 166:472-479.

II. Office of national Statistics: Demografic and cancer statistics 1996-2000.

12. Kempainen M, Raiha I, Rajala T, Souranda L: Characteristics of colorectal cancer in elderly patients. Gerontology 1993, 39:222-227.

13. Arai T, Takubo K, Sawabe M, Esaki Y: Pathologig characteristics of colorectal cancer in the elderly; a retrospective study of 947 surgical cases. Clin Gastroenterology 2000, 31 : 67-72.

14. Menke H, Graf J, Heintz A, Klein A, Junginger T: Risk factors of perioerative morbidity and mortality with special reference to tumor stage, site and age. Zentralbl Chir 1993, I I 8:40-46.

15. Edna TH, Bjerkeset T: Colorectal cancer in patients of over $\mathbf{8 0}$ years of age. Hepatogastroenterology 1998, 45:2। 42-2। 45.

16. Poon R, Law W, Chu K, Wong J: Emergency resection and primary anastomosis for left-sided obstructing colorectal carcinoma in the elderly. Br J Surg 1998, 85: I539- I542.

17. Colorectal Cancer Collaborative Group: Surgery for colorectal cancer in elderly patients; A systematic review. Colorectal Cancer Collaborative Group. Lancet 2000, 356:968-974.

\section{Pre-publication history}

The pre-publication history for this paper can be accessed here:

http://www.biomedcentral.com/1471-2407/5/153/pre pub

Publish with Bio Med Central and every scientist can read your work free of charge

"BioMed Central will be the most significant development for disseminating the results of biomedical research in our lifetime. "

Sir Paul Nurse, Cancer Research UK

Your research papers will be:

- available free of charge to the entire biomedical community

- peer reviewed and published immediately upon acceptance

- cited in PubMed and archived on PubMed Central

- yours - you keep the copyright

Submit your manuscript here:

http://www.biomedcentral.com/info/publishing_adv.asp
BioMedcentral 